\title{
International evidence on the predictability of returns to securitized real estate assets: econometric models versus neural networks
}

Article

Accepted Version

Brooks, C. and Tsolacos, S. (2003) International evidence on the predictability of returns to securitized real estate assets: econometric models versus neural networks. Journal of Property Research, 20 (2). pp. 133-155. ISSN 1466-4453 doi: https://doi.org/10.1080/0959991032000109517 Available at https://centaur.reading.ac.uk/21317/

It is advisable to refer to the publisher's version if you intend to cite from the work. See Guidance on citing.

To link to this article DOI: http://dx.doi.org/10.1080/0959991032000109517

Publisher: Routledge

All outputs in CentAUR are protected by Intellectual Property Rights law, including copyright law. Copyright and IPR is retained by the creators or other copyright holders. Terms and conditions for use of this material are defined in the End User Agreement. 


\section{CentAUR}

Central Archive at the University of Reading

Reading's research outputs online 
This is an Author's Accepted Manuscript of an article published in the Journal of Property Research (2003) [copyright Taylor \& Francis], available online at: http://www.tandfonline.com/10.1080/0959991032000109517. 


\section{International Evidence on the Predictability of Returns to Securitised Real Estate Assets:} Econometric Models versus Neural Networks ${ }^{\dagger}$

Chris Brooks (corresponding author), ISMA Centre, PO Box 242, The University of Reading,

Whiteknights, Reading RG6 6BA;

tel.: (+44) 11893167 68; fax: (+44) 11893147 41; e-mail: C.Brooks@ reading.ac.uk

and

Sotiris Tsolacos, Jones Lang LaSalle, 22 Hanover Square, London, W1A 2BN

E-mail: sotiris.tsolacos@eu.joneslanglasalle.com

April 2003

JEL Classifications: C32, C52

Keywords: real estate returns, vector autoregressive models, neural networks, forecasting.

\footnotetext{
${ }^{\dagger}$ The authors are grateful to three anonymous referees and participants of the $17^{\text {th }}$ annual meeting of ARES for useful comments on an earlier version of this paper. We also thank Ramo Gencay for supplying the programs, which were modified by the first author, to compute the neural network forecasts. The usual disclaimer applies.
} 


\title{
International Evidence on the Predictability of Returns to Securitised Real Estate Assets: Econometric Models versus Neural Networks
}

\begin{abstract}
This paper examines the performance of various statistical models and commonly used financial indicators for forecasting securitised real estate returns for five European countries: the UK, Belgium, the Netherlands, France and Italy. Within a VAR framework, it is demonstrated that the gilt-equity yield ratio is in most cases a better predictor of securitised returns than the term structure or the dividend yield. In particular, investors should consider in their real estate return models the predictability of the gilt-equity yield ratio in Belgium, the Netherlands and France, and the term structure of interest rates in France. Predictions obtained from the VAR and univariate time-series models are compared with the predictions of an artificial neural network model. We find that, whilst no single model is universally superior across all series, accuracy measures and horizons considered, the neural network model is generally able to offer the most accurate predictions for 1-month horizons. For quarterly and half-yearly forecasts, the random walk with a drift is the most successful for the UK, Belgian and Dutch returns and the neural network for French and Italian returns. Although this study underscores market context and forecast horizon as parameters relevant to the choice of the forecast model, it strongly indicates that analysts should exploit the potential of neural networks and assess more fully their forecast performance against more traditional models.
\end{abstract}

\section{Introduction}

Accurate prediction of returns on securitised real estate assets is a topic of considerable interest that has led researchers to deploy alternative theoretical models and econometric techniques to track the historical time-series behaviour of returns on real estate traded assets, REITs and mimicking portfolios comprising real estate backed stocks. Inputs into the models are macroeconomic and financial series that contain useful information about future business activity and market expectations. Commonly tested series include various measures of interest rates, the term spread, expected and unexpected inflation, industrial production, the dividend yield and the yield spread between corporate and government bonds.

Based on a multifactor arbitrage pricing model and cross-sectional regression analysis, Chan, Hendershott and Sanders (1990) demonstrated a systematic effect of the term structure and the change in the default spread (difference between the yields on low-grade corporate bonds and Treasury bonds) on the returns of mimicking real estate portfolios these authors constructed. The estimation of a multifactor asset pricing model with the generalised method of moments by Liu and Mei (1992) showed that the Treasury Bill rate and the capitalisation rate on equity REITs were significant factors in the predictability of excess returns on equity REITs. Using a similar methodology and estimation procedure, Mei and Liu (1994) showed that the statistical significance of the predetermined variables depends on the type of real estate stock return series. For example, the Treasury Bill rate was significant in all classes of real estate stock return series but the overall stock market dividend yield was significant for the group of real estate holding companies and real estate building companies but not significant for 
equity and mortgage REITs. Similarly, the capitalisation rate on equity REITs was significant in the latter two classes but not in the former two.

Ling and Naranjo (1997) studied, within a multifactor asset pricing model, the effect of a set of predetermined variables on excess returns (returns in excess of the risk free rate) for four different portfolios constructed using REIT data and appraisal based returns by region, property type and estimates of transaction-based price indices. A non-linear SURE estimation that was applied to fortyone portfolios belonging to four groups showed that real per capita consumption affected real estate returns in the fixed-coefficient model whereas the term structure of interest rates and unexpected inflation were significant when the coefficients were allowed to vary over time. Further empirical evidence on the linkages between returns or excess returns and economic and financial factors (relating to both equity and bond markets) can be found among other studies in Mueller and Pauley (1995), Chen, Hsieh and Jordan (1997) and Peterson and Hsieh (1997).

Authors have also obtained empirical results from other methodologies. McCue and Kling (1994) used vector autoregressions and examined the sensitivity of real estate returns (purged of their stock market influences) to a set of predetermined variables and found strong evidence for the role of nominal interest rates. In a similar study with UK data, Brooks and Tsolacos (1999) concluded that when general stock market influences are extracted from the UK real estate stock returns, it is difficult to explain their residual movement on the basis of the information contained in the commonly used macroeconomic and financial variables. Variance decompositions and impulse responses provided only weak evidence for the significance of the term structure and unexpected inflation. In a subsequent study, Brooks and Tsolacos (2001a) examined relationships using the raw return series (not adjusted for general stock market influences) and found that returns are related to the term structure of interest rates but not to the short- or long-run rates. Granger causality tests confirmed causal relationships from the spread variables to the return series but variance decomposition showed that only ten percent of the variation in property stock returns was explained. In another UK study, Lizieri and Satchell (1997) estimated regimeswitching models and found the existence of a non-linear relationship between property company share prices and real interest rates. During periods of relatively high interest rates, real estate share prices fell sharply and exhibited little volatility. However, during periods of relatively low interest rates, price movements became more erratic.

In addition to estimating linkages between real estate stock returns and macroeconomic or financial series, a number of studies have considered other factors as possible determinants of real estate return movements. Chan, Hendershott and Sanders (1990), for example, examined whether the sensitivity of real estate returns depends on the degree of leverage of REITs. Their results showed that more levered REITs are more sensitive to predetermined variables. Through a cross-sectional study with dummy 
variables, Peterson and Hsieh (1997) examined the effect of equity and non-equity REIT, REIT captivity (if a REIT has a relationship with the sponsor, advisor or affiliates) and advisory types (real estate, financial or other) on REIT performance. When these characteristics are examined within a model that contains stock and bond market influences, the results show that it is only the REIT type that differentiates REIT performance. Allen, Madura and Springer (2000) looked at the relevance of asset structure, financial leverage, management strategy and degree of specialisation on REIT returns. They found no evidence that these characteristics affect the sensitivity of REITs to changes in short- and long-term interest rates, which in their study proved to be very significant influences on both equity and non-equity REIT returns.

The above brief review of studies on the predictability of real estate returns illustrates methodologies that provide the basis for the testable pre-determined variables along the lines of stock market studies that have guided research work on real estate assets. Authors examine the impact of the pre-determined variables mainly within multi-factor asset pricing models. The empirical representations of these models take the form of multiple regressions (either one equation or in system form) estimated with techniques such as least squares, generalised method of moments and SURE. A number of studies have, however, studied the effect of these factors within more general approaches including vector autoregressions, vector error correction models and regime switching techniques. The economic and financial variables that the existing literature has identified as significant in the predictability of returns include measures of interest rates, the term spread of interest rates, dividend yields, inflation, unexpected inflation and the gilt-equity yield ratio. These variables do not differ from those receiving support in the general stock market (see Mi and Maddala, 1999). However, unlike stock market studies, the real estate literature has paid sparse attention to the formal assessment of the forecasting performance of the methodologies used for modelling real estate returns. Moreover, it is not clear how methodologies with no lagged relationships can actually be used for forecasting especially when predictions of the future values of these explanatory variables are difficult to obtain.

Three studies are the exception to this omission and extend the analysis to assess the benefits from the predictability of the real estate return cycle. Mei and Liu (1994) obtain out of sample excess return predictions by estimating their model for the first ten years and producing forecasts through rolling regressions for the next ten years. Subsequently, these authors utilise the predictions of the models estimated for alternative real estate stock return series and construct a passive buy and hold portfolio which is used as the benchmark (along with the S\&P 500 mean excess returns) for comparing whether superior returns are possible for two active portfolios: a long portfolio and a long and short portfolio. Starting in 1981 with a wealth of $\$ 100$ and selling the portfolios at the end of 1989, a long and short strategy would have yielded between $\$ 78$ and $\$ 289$ and a long strategy between $\$ 34$ and $\$ 141$. The analysis of Mei and Liu showed that a long and a short strategy would have fetched $\$ 238.20$ for 
homebuilder stocks (one of the real estate portfolios examined) at the end of 1989 over and above a passive strategy. This figure would have been $\$ 337.13$ if the investor were trading both the S\&P500 and the homebuilder portfolio.

In the UK context, Brooks and Tsolacos (2001b) perform a similar exercise. These authors focus on a single real estate return series (the Thomson Datastream UK Property Index) but they explicitly examine the forecasting performance of three different methodologies. The first forecasting methodology is the unconditional mean of a trailing sample of 200 observations of real estate returns. Such a model is identical to a random walk with drift in the log of the prices. The other two forecasting methodologies are an ARMA model and a vector autoregressive model (VAR). Along with real estate returns, two other variables were included in the VAR system: the term structure of interest rates and the gilt-equity yield ratio. Brooks and Tsolacos used these methodologies to produce 160 out of sample forecasts for horizons of up to 6 months. The forecast evaluation criteria showed that the long-term mean and the ARMA specification are more appropriate for forecasting in the short-term (one month ahead) than the more complex VAR model. However, the latter model produces the highest proportion of correct return sign predictions. For the six-month ahead forecasts, the long-term mean return produces the most accurate forecasts under all evaluation measures.

Subsequently, Brooks and Tsolacos developed trading rules. The first rule is 'invest in the real estate stock index if the return during the next period is forecast to be positive otherwise hold Treasury bills'. The second rule is 'invest in the index only if the return for the next month is greater than the average return over the whole sample period otherwise hold Treasury bills'. The simple average annualised return to simply holding the property index throughout is 8.07\% (January 1968 to January 1998). Overall, some of the models are able to modestly improve on this profitability. The best performing models in aggregate are the VAR models, which produce returns of $9.26 \%$ per annum for the one-step ahead forecasts. The results also showed that trading on the basis of the one-step ahead forecasts is more profitable than trading on the basis of the six-step ahead forecasts. When transaction costs are taken into account (bid/ask spread, stamp duty and commission) and there are approximately 3-4 trades per year, the gross return of $9.26 \%$ is reduced by about $6 \%$. Thus, in net terms, these trading rules did not outperform the buy and hold strategy.

A third study by Wilson, Okunev, Ellis and Higgins (2000) focuses on predicting turning points in securitised real estate return series in the US, the UK and Australia. These authors employ ARIMA and exponential smoothing models to identify turning points and compare the performance of these models with a spectral technique. The former two models study the behaviour of returns and forecast turning points from the time domain whereas the latter provides a view from the frequency domain. In this way, the authors attempt through spectral analysis to identify hidden cycles of differing lengths and 
amplitudes in the return series. The findings of this study showed that the spectral analysis, which assumes a four-year cycle in the data, performed well in capturing turning points in all quarterly series of real estate returns. Moreover, Wilson et al found that spectral analysis identified more clearly turning points than ARIMA and outperformed the exponential smoothing models, which as expected did not predict the turning points. Further to the evidence on the ability of different models to predict turning points, this study alerts researchers about the need to study the cyclical behaviour of real estate returns from the frequency domain point of view.

The objectives of the present study are twofold. First, it provides international evidence (from five European countries: the UK, France, the Netherlands, Belgium and Italy) on the significance of the giltequity yield ratio, the term structure of interest rates and the dividend yield in the predictability of real estate returns. These variables have received empirical support in studies of general stock returns and are closely watched by investors since they convey information about monetary policy and expectations about general stock market trends. The gilt-equity yield ratio is an information variable that, despite the empirical support it has received in general stock market studies, has not been widely examined in the context of real estate returns. It could be argued that since the inception of European Monetary Union, a harmonisation process in the financial environment has been underway. If such an expected harmonisation has been achieved, signals from these three predictive factors should be priced consistently across the five European countries. However, if differences persist, the real estate return behavioural equations could be characterised by different parameters if not different functional forms altogether. That is, in the empirical inquiry of the present paper, the three variables may have different effects on real estate returns, insinuating distinct investor behaviour.

The second area of interest in this paper is to explore the forecasting capability of alternative methodologies. Evaluating the forecasting performance of different specifications will increase knowledge as to which models are best for forecasting and are probably the most appropriate to base trading rules upon. Forecasts of real estate returns are useful for portfolio analysis and for those considering taking positions in the market. For example, a number of studies (Myer and Webb, 1994; Barkham and Geltner, 1995, and Seiler, Webb and Myer, 1999a, 1999b) find evidence of the indirect market leading the direct market. Therefore, according to these studies, by forecasting the indirect market, analysts receive an even earlier signal of the future direction of direct markets. Recently, Stevenson (2001) emphasises that the forecasting of returns is an important task when the construction of future optimal portfolios is considered. Such comparative forecasting work has been undertaken in direct real estate (examples include Chaplin 1998, 2000, Brooks and Tsolacos, 2000 and McGough, Olkkonen and Tsolacos, 2000) but it has not been pursued in the securitised real estate markets. 
This study initially applies a vector autoregression (VAR) system to examine the predictive ability of the gilt-equity yield ratio, the term structure the dividend yield. Subsequently, the forecast performance of the VAR system in each of the countries is assessed along with that of two other methodologies: an autoregressive moving average (ARMA) model and a neural network (NN) model. Such methodologies facilitate the task of ex ante out of sample forecasting. Within the VAR system for example, the predetermined variables will be forecast by the model as well as real estate stock returns. ARMAs have proven successful for time-series forecasting and VARs for forecasting systems of interrelated timeseries in economics and finance. The VAR model makes the implicit assumption that the relationships between real estate returns and the three predictive variables are linear. Hence it provides a good benchmark from which to test the forecast performance of a neural network model, which allows for the presence of non-linearities in the relationships.

Neural networks are a class of statistical models whose functional form is loosely derived from the way that computation is performed by the brain. Neural networks derive their attractiveness from their ability to fit any set of data to a given arbitrary level of accuracy, provided that the number of connections is sufficient. Several recent papers have applied neural network models to the prediction of prices in direct real estate (see, for example, Tay and Ho, 1991; Evans et al., 1992; Connellan and James, 1998) and the results appear to have been largely encouraging. However, other studies have not found strong evidence that neural networks outperform alternative methodologies (for example the studies by Worzala, Lenk and Silva, 1995 and Wong, So and Hung, 2002 on residential markets in the US and Hong Kong respectively). In the context of stock markets more generally, Donaldson and Kamstra (1996) find that the neural network method generally outperforms volatility forecasts from a variety of traditional linear models for daily stock data in the USA, Canada, Japan and the UK. Similar support is provided by Qi and Maddala (1999) who found that the neural network method outperforms linear forecasts and naïve model predictions. But in the presence of transaction costs, it is only the switching portfolio based on the linear forecasts that outperforms the market. The evidence from these studies warrants an examination of the forecasting performance of neural networks and forecast comparisons with naïve and linear forecast frameworks.

The remainder of this paper is organised into four sections. Section two describes the data as well as the VAR system, the ARMA process and the neural network used in this study, and outlines the forecasting criteria. Section three presents the estimation results and evaluates the forecast output. Finally, section four concludes and discusses the implications of this study. 


\section{Models, forecast criteria and data}

\subsection{Modelling and forecast methodologies}

VAR specification

The attribution of the variation of real estate returns to the equity-gilt yield ratio, the term structure and the dividend yield in each of the five countries is examined within a VAR framework and F-tests, forecast error variance decompositions and impulse responses of real estate returns to disturbance shocks are calculated. The choice of the three predictive factors is guided by the results of the existing literature. Incorporating these variables into a VAR framework resembles the studies of McCue and Kling (1994) and of Brooks and Tsolacos (1999) on securitised real estate returns. This line of investigation is not uncommon in general stock market returns when one of the aims of the study is assessing forecasting performance (see for example Pesaran and Timmerman (1995) and Qi and Maddala (1999)).

This VAR system that is estimated in each of the countries is given by equation (1).

$Y_{t}=\beta_{0}+\beta_{1} Y_{t-1}+\ldots+\beta_{m} Y_{t-m}+u_{t}$

where $Y$ is the set (or $4 \times 1$ vector) of variables included in the system, the $\beta$ terms give the sets of coefficient vectors $\left(\beta_{0}\right.$ is a $4 \times 1$ vector of constants, $\beta_{1}, \ldots, \beta_{m}$ are $4 \times 4$ matrices of coefficients on the lagged variables, $m$ represents the number of lags of each variable in each equation), and $u_{t}$ is a vector of disturbance terms (or innovations) which are assumed to be mutually uncorrelated and independent of the lagged $Y \mathrm{~s}$. The numbers of lags of each variable to be included in the VAR are chosen using multivariate generalisations of Akaike's and Schwarz's Bayesian information criteria.

The gilt-equity yield ratio (GEYR) is considered as a predictor which can provide useful information to investment managers and market analysts in determining whether to invest in equities or government bonds (Clare, Thomas and Wickens, 1994; see also Brooks and Persand, 2001). It is defined as the ratio of the income yield on long-term government bonds to the dividend yield on equities and is assumed to have a long-run equilibrium level, deviations from which are taken to indicate that equity prices are at an unsustainable level (Brooks and Persand, op cit). Equities are considered expensive relative to bonds if this ratio becomes high relative to its long-run level. If the dividend yield falls, the GEYR becomes too high so that equities are thought expensive relative to bonds. Levin and Wright (1998) state that if bond yields do not fall, the low level of equity yields is unlikely to be sustained. When such a situation emerges, it is expected that the equity yields will have to increase via a fall in equity prices. On the other hand, when the GEYR is too low, equity prices are expected to rise in order to restore the equilibrium relationship. In applying this ratio to indirect real estate returns, it is assumed that traded real estate assets possess the characteristics of equities. Brooks and Tsolacos (2001) provide evidence that VAR models containing the gilt-equity yield ratio can improve upon the short-term predictions (for 
example for one to two months ahead) of pure time-series and naïve techniques in the context of the UK.

There has been a substantial volume of literature in finance and macroeconomics that uses the term structure of interest rates (defined as the difference between the yields on long- and short-term bonds) as predictor of economic activity, inflation and asset prices (representative studies include Bernanke 1990; Chen, 1991, Estrella and Hardouvelis, 1991, Hardouvelis, 1994; Estrella and Mishkin, 1997; Gerlach and Smets, 1997, Berk, 1998). Similarly, measures of the term structure of interest rates have been extensively used in research work aiming to explain the movements of real estate returns. Theoretical explanations as to how the term structure affects real economic activity have been provided through a consumption capital asset pricing model (see Harvey, 1988) or through the effects on the IS and LM curves (see Estrella and Mishkin, 1997). Bernanke (1990) argued that interest rates and spreads contain information about the future course of the economy that is not included even in the index of leading indicators. Expectations of increases in interest rates are associated with a steepening curve and lower future investment and output. A short-lived real demand shock or monetary shock can result in higher short-term interest rates flattening the yield curve. The long-term rate tends to increase in response to the increase in the short-term rate but by less than the short rate (Estrella and Mishkin 1997). Investment and output are expected to fall in the short run but not in the long run as the shock is expected to be short lived. Since the term structure contains information concerning future (both near future and longer term) real activity, it also embodies information about profitability and equity prices.

Research findings about the significance of the term structure in explaining the variation in real estate returns are conflicting. Chan, Hendershott and Sanders (1990) provided supporting evidence that the term structure affects real estate market returns, whereas Liu and Mei (1992) did not find such evidence. Ling and Naranjo (1997) found that the spread variable becomes important in particular periods. Brooks and Tsolacos (1999) did not show strong evidence to support to the view that the term structure explains real estate return movements in the UK. However, their study examined the variation in real estate returns after purging general stock market influences and therefore the effect of the term structure may already have been removed. In another UK study, Brooks, Tsolacos and Lee (2000) examined the cyclical regularities of the real estate return cycle and a set of macroeconomic, financial and property market variables after decomposing the series to extract their secular and cyclical variations. This study provided evidence that the interest rate spread cycle tends to exhibit a procyclical relationship with the real estate return cycle leading the latter by three to six months.

The third financial indicator, the dividend yield, has also received attention in empirical work on the predictability of general stock returns (Campbell and Shiller, 1988; Fama and French, 1988; Ferson and Harvey, 1991; Kothari and Shanken 1997). Movements in the dividend yield are assumed to capture 
expectations concerning corporate profitability, future dividends and stock prices. Fama and French (1988) note that the dividend yield is a noisy proxy for expected stock prices and returns because it partly reflects expected dividend growth. Optimism about future dividends produces high stock prices relative to current dividends and a current low dividend yield. Liu and Mei (1992) used the dividend yield to explain equity REIT returns based on the assumption that changes in dividend yields reflect expectations about long-term economic conditions and also that such changes capture the same predictable components of returns as the interest rate spreads. Their results did not, however, establish the dividend yield as a significant variable in a model for explaining equity REIT returns. In the study of Brooks and Tsolacos (1999), the dividend yield was found to have an effect (but not very strong) on real estate returns for three months. In accordance with a priori expectations, Brooks, Tsolacos and Lee (2000) established a countercyclical relationship between the real estate stock price cycle and the dividend yield cycle. The results showed a rather strong contemporaneous relationship suggesting that the cycles of real estate stock prices and dividend yields are coincident and therefore that the dividend yield does not provide any leading information about the real estate stock price cycle.

A few words are necessary concerning the possible existence of high correlations between the explanatory variables employed in the VAR. A calculation of these for the 5 countries (not shown due to space constraints but available from the authors on request) suggests that only the dividend yield and real estate returns have a non-negligible contemporaneous correlation. The coefficients for this correlation are negative and of the order of -0.7 for Belgium, France, the Netherlands and the UK. This may make it difficult to tease out the individual impacts of the two variables for these countries, resulting in large coefficient standard errors, although the point forecasting accuracy will not be affected.

\section{ARMA Modelling}

The ARMA model for real estate returns is given by equation (2):

$$
D R E_{t}=\mu+\sum_{i=1}^{p} \phi_{i} D R E_{t-i}+\sum_{j=0}^{q} \theta_{j} u_{t-j}
$$

where $D R E$ is the continuously compounded percentage return on real estate traded stocks in the five countries considered, $p$ is the order of the autoregressive part (AR), $q$ is the order of the moving average (MA) part, and $\theta_{0}=1$. The orders of the AR and MA parts are determined by Akaike's and Schwarz's Bayesian information criteria.

\section{Neural Networks}

The primary advantage of neural networks over more conventional econometric techniques lies in their ability to model complex, possibly non-linear processes without assuming any prior knowledge about 
the functional form of the underlying data generating process. The fully flexible functional form makes them particularly suited to a financial application where non-linear patterns are often deemed to be present, but an adequate structural model is conspicuously absent. By far the most popular type of model, and the one employed here, is known as a single hidden layer feed-forward neural network. The model can be specified as follows. The structure consists of three layers: the inputs (akin to regressors in a linear regression model), that are connected to the output(s) (the regressand) via a hidden or intermediate layer. From an econometric perspective, the problem reduces to one of estimating the "synaptic" weights or connection strengths between the layers. Formally, the network model can be written

$D R E_{t}=\sum_{j=1}^{N} \beta_{j} \varphi\left(\sum_{i=1}^{m} w_{i j} Z_{i, t-1}+b_{j}\right)+u_{t}$

where the number of hidden units in the intermediate layer is $N, m$ is the number of inputs, $Z$ are the inputs, $\beta$ represents the hidden to output weights, and $w$ and $b$ represent the input to hidden weights ( $b$ is also known as a "bias" term, akin to the constant term used in standard linear regression equations), and $\phi$ is an activation function. The inputs (or regressors) could be selected to be any variables thought to influence the output (dependent variable). However, we use the lagged values of the same variables that are used in the VAR model. Thus, such a model might loosely be thought of as a non-linear form of the real estate equation from the VAR specification. The parameters are estimated using non-linear least squares (NLS). Since this is a non-linear optimisation technique and the model is complex, an analytical formula for calculating the parameter estimates does not exist, and instead an iterative search procedure must be employed. NLS estimates are computed in this application using an application of the Levenberg-Marquardt algorithm (see Marquardt, 1963). The activation function for the hidden layer is the sigmoid

$$
\varphi(p)=\frac{1}{1+\exp (-p)}
$$

where $p$ represents all of the parameters in the function $\varphi$. One possible side effect of this is that the resulting estimates could represent local rather than global optima, but this is one of the prices that must be paid for the flexibility and complexity of such models.

\subsection{Forecast Production and Evaluation}

Following estimation of the neural network, ARMA and VAR models with the real estate return series from the five countries, their forecasting performance is examined. For producing the forecasts, the whole sample is split into two parts, with the first 60 observations being used for in-sample parameter estimation, and then a $1,2, \ldots, 6$ month ahead forecast is produced. The sample is then increased by one observation, the model parameters are then re-estimated using observations 1 to 61 , and a further set of forecasts produced and so on until the sample has been exhausted. In addition to the ARMA and VAR 
specifications, a random walk model with a drift is deployed to produce the benchmark forecasts. The assumption in a random walk model is that the stock price series wanders up and down randomly with no tendency to revert to any particular trend or point. Real estate stock prices, following a shock that lowers or increases their value, are assumed by this model to show no tendency to return to a particular mean level. Thus a shock has permanent effects on price. This random walk model is given by equation (4):

$D R E_{t}=\alpha+u_{t}$

where $\alpha$ is the drift and $e_{t}$ is a random error term. A random walk model in the log-levels implies that return forecasts will be equal to the long-term mean of the returns series (i.e. the drift).

The forecasts are evaluated with three criteria: the mean error (ME), the root mean squared error (RMSE) and the mean absolute error (MAE). The mean error denotes bias and represents the simplest available measure of forecast accuracy. A mean error of zero indicates no bias (positive or negative) in the forecasts. However, large positive and negative forecast errors may cancel themselves out and result in low mean errors. The RMSE and MAE are broadly similar measures that are employed to give an indication of the size of the errors. Both these measures are appropriate when comparisons of forecasts are made, and have been widely employed in the literature. RMSE provides a quadratic loss function, and so may be particularly useful in situations where large forecast errors are disproportionately more serious than smaller errors. Thus, RMSE is said to have a strong ability to discriminate sharply between good and bad models. This may, however, also be viewed as a disadvantage if large errors only proportionately more serious than small errors, and hence MAE is also employed.

\subsection{Data}

The real estate stock price series in each country comprises a market capitalisation weighted index of the companies that make the top $80 \%$ of the real estate sector. The dividend yield is the overall stock market dividend yield (London, Brussels, Amsterdam, Paris and Milan). The term spread is defined as the difference between the ten-year government bond yield and the yield on the three-month Treasury bill. The gilt-equity yield ratio is constructed from the respective interest rates and dividend yield series (10 year government bond yield divided by the dividend yield in the respective country). The source for all data series is Thomson Datastream. The GEYR, term spread, and dividend yield data enter the analysis in levels form, since they are stationary, while the real estate indices are transformed to continuously compounded returns. The sample period is January 1991 to February 2001 providing 122 observations for analysis. 
Table 1: Summary statistics and Unit Root Tests

Panel A: Real Estate Return Summary Statistics

\begin{tabular}{lccccc}
\hline & UK & Belgium & The Netherlands & France & Italy \\
\hline Minimum & -15.60 & -10.13 & -8.87 & -10.37 & -21.09 \\
Maximum & 14.28 & 15.47 & 9.27 & 10.08 & 38.42 \\
Mean & 0.45 & 0.16 & 0.03 & 0.16 & -0.05 \\
Variance & 29.38 & 16.60 & 12.59 & 15.75 & 65.92 \\
Skewness & -0.40 & 0.27 & 0.27 & -0.02 & 0.95 \\
Excess Kurtosis & 0.22 & 1.38 & -0.01 & 0.33 & 4.26 \\
BJ - Normality & 3.45 & $11.11^{* *}$ & 1.42 & 0.54 & $109.68^{* *}$ \\
\hline & \multicolumn{7}{c}{ Panel B: Unit Root Tests } \\
\hline Real Estate Returns & $-166.78^{* *}$ & $-26.26^{* *}$ & $-25.99^{* *}$ & $-373.92^{* *}$ & $-30.87^{* *}$ \\
GEYR & $-150.36^{* *}$ & $-13.05^{* *}$ & $-27.81^{* *}$ & $-43.76^{* *}$ & $-7.06^{* *}$ \\
Term Spread & $-8.83^{* *}$ & $-9.94^{* *}$ & $-13.14^{* *}$ & $-8.57^{* *}$ & $-32.37^{* *}$ \\
Dividend Yield & -2.29 & $-5.15^{* *}$ & $-2.90^{*}$ & -2.82 & $-6.70^{* *}$ \\
\hline
\end{tabular}

${ }^{1} \mathrm{BJ}$ is the Bera-Jarque test for normality, distributed as a $\chi^{2}(2)$ under the null. * and $* *$ denote significance at the $5 \%$ and $1 \%$ levels respectively. The unit root test employed is the augmented Dickey-Fuller test with 12 lags of the dependent variable; the critical values are $-2.89(5 \%)$ and $-3.51(1 \%)$.

Panel A of Table 1 provides summary statistics for the variables used. In terms of the minima and maxima of the series, the Italian series shows the largest returns, both positive and negative, and its variance is also considerably higher than that of the other series. The mean return is highest for the UK, while it is negative for Italy and virtually zero $(0.03 \%$ per month) for the Netherlands. Whilst the Netherlands returns have the lowest variability, overall the UK followed by France would be the most attractive as stand-alone investments. The UK and French series are skewed to the left while the Belgian, Dutch and Italian return distributions are skewed to the right. All series except the Netherlands are fat tailed, as shown by the positive coefficients of excess kurtosis. Only the Belgian and Italian returns show statistically significant departures from normality, however. Panel B of Table 1 shows the results of augmented Dickey-Fuller unit root tests on all of the variables in the VAR. For all series with the exception of dividend yields, the unit root null hypothesis is resoundingly rejected at the $1 \%$ level, whilst for the UK and French dividend yields however, the unit root null would only be rejected at the $10 \%$ significance level.

The French, Belgian and Dutch real estate series move very closely together over time, as shown in Figure 1, whilst the Italian series is far more variable than the others and is rather isolated, especially from early 1998 onwards. This volatility can be attributed to the very limited size of quoted property sector and the volatile nature of few leading players. It also demonstrates the changing attitudes of investors towards the Italian quoted real estate sector. In 1998, Banca San Paolo spun-off its property business as Beni Stabili, which become Italy's second biggest property stock. In 2001, CFI bought a controlling stake in Beni Stabili, which became popular with analysts. However, in 2002, Beni Stabili 
sold its Telecom Italia stake at a price below expectations and it quickly fell out of favour with investors.

Figure 1: European Real Estate Returns: January 1991 - February 2001

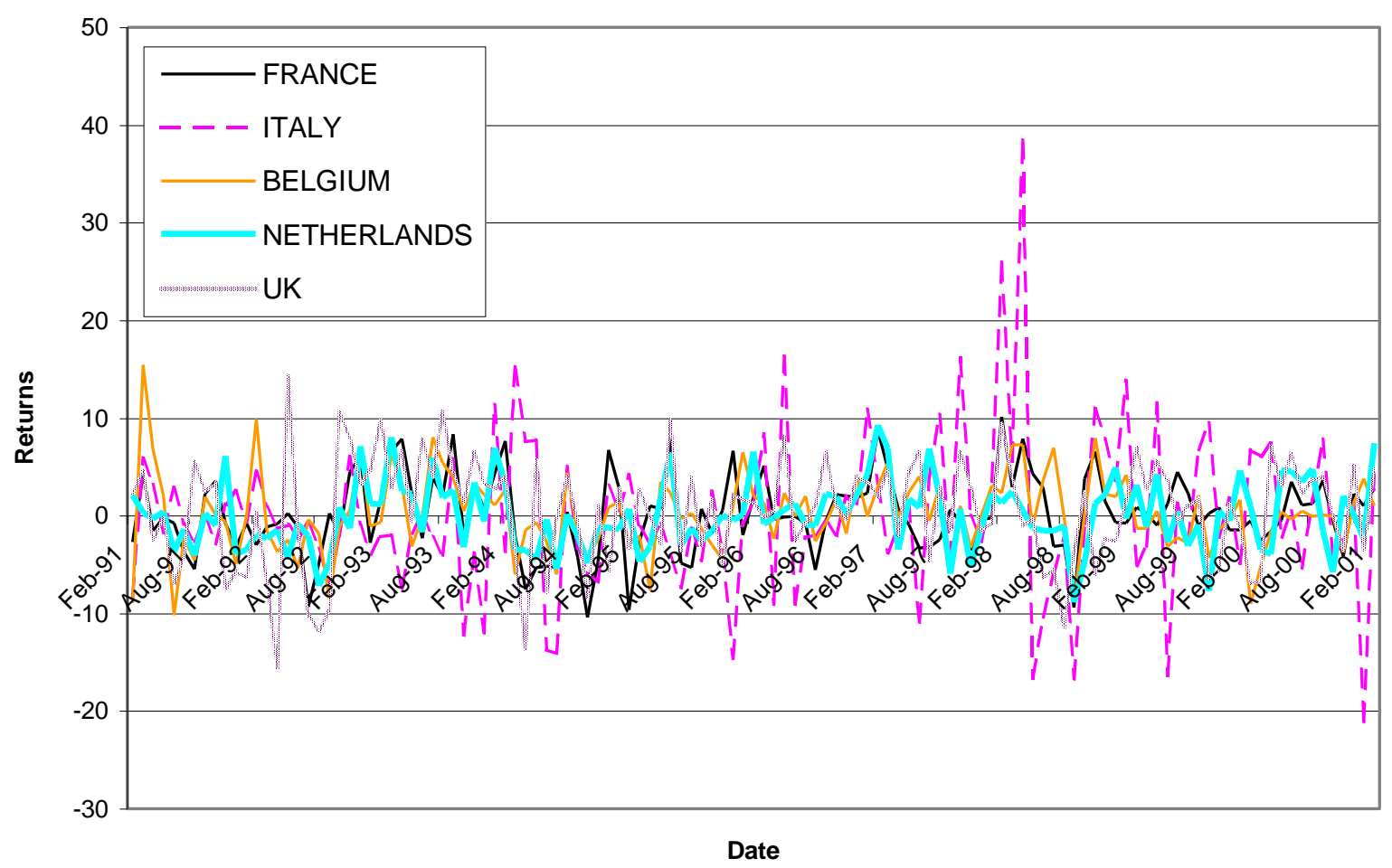

\section{Estimation results and forecast outputs}

\subsection{VAR and ARMA model selection}

Table 2 presents the optimal number of lags of each variable in each equation of the VAR models, and the univariate ARMA models according to Schwarz's Bayesian and Akaike's information criteria. The maximum permissible number of lags is set (arbitrarily) to 5 for the VAR and 12 for the autoregressive part and 12 for the moving average part, of the ARMA models. The model orders are determined and the VAR analysis is conducted on the whole sample of data.

Table 2. Lag Length Selection for $\operatorname{ARMA}(p, q)$ and VAR Models

\begin{tabular}{ccccc}
\hline & \multicolumn{2}{c}{ Univariate ARMA Models } & \multicolumn{2}{c}{ VAR Models } \\
\hline UK & SBIC & AIC & SBIC & AIC \\
Belgium & $(3,2)$ & $(6,12)$ & 1 & 3 \\
The Netherlands & $(4,2)$ & $(10,9)$ & 1 & 1 \\
France & $(1,1)$ & $(7,10)$ & 1 & 1 \\
Italy & $(1,1)$ & $(7,6)$ & 1 & 1 \\
\hline
\end{tabular}

For the VAR models, Schwarz's criterion selects one lag as optimal for all countries, while Akaike's selects three lags for the UK and one lag for all others. It is probably unsurprising that small model 
orders are selected in all cases, since introducing a further lag into a VAR system containing 4 equations will require the estimation of 4 further parameters, and the sample size used here is relatively modest. Schwarz's criterion is well known for the parsimonious models that it chooses, while Akaike's criterion can be very profligate, and has a tendency to select the largest model that is consistent with the data.

For the univariate ARMA models, Schwarz's criterion selects one lag of each of the autoregressive and moving average parts for the Netherlands, France and Italy, with larger models for the other two countries. In the case of the univariate models, Akaike's criterion selects far bigger model orders of between $(7,6)$ for France and $(10,9)$ for Belgium. It is also evident that the Belgian real estate index contains the strongest linear relationship with its previous values compared with those of other countries.

In the interests of brevity, in all ensuing analysis, we employ only the VAR lag lengths selected by SIC, and we examine the forecasting ability of univariate models whose orders have been chosen using both AIC and SIC. Schwarz's information criterion selects one hidden unit for each neural network model, and one lag of each variable as optimal.

\subsection{VAR estimates for the predictive factors}

Table 3 presents the results of block $F$-test restrictions, which involve restricting all of the lags of a particular variable to have zero coefficients. In this case, since the model orders are all one for the VARs, this $F$-test is equivalent to the usual $t$-test on each of the lagged values. Such tests can be used to gain an idea of whether a series is related to previous values of one or more other series in the VAR. Any cell entry smaller than 0.05 would indicate that the variable under consideration significantly affected the future values of the real estate returns.

Table 3: Marginal significance levels ( $p$-values) associated with $F$-tests that all lags have no explanatory power on the real estate return equation of the VAR system and Autocorrelation Tests on the Residuals of the Estimated Models.

\begin{tabular}{|c|c|c|c|c|c|}
\hline \multirow[t]{2}{*}{ Country } & \multicolumn{4}{|c|}{ Lags of Variable } & \multirow{2}{*}{$\begin{array}{l}\text { Ljung-Box } \\
\text { Q* Statistics }\end{array}$} \\
\hline & $\begin{array}{l}\text { Real estate } \\
\text { returns }\end{array}$ & GEYR & $\begin{array}{c}\text { Term } \\
\text { spread }\end{array}$ & $\begin{array}{c}\text { Dividend } \\
\text { yield }\end{array}$ & \\
\hline UK & 0.24 & 0.17 & $0.08^{*}$ & 0.53 & 13.43 \\
\hline Belgium & 0.40 & $0.00^{* *}$ & 0.56 & $0.05^{* *}$ & 8.07 \\
\hline The Netherlands & $0.06^{*}$ & $0.03^{* *}$ & 0.91 & 0.12 & 5.02 \\
\hline France & $0.02^{* *}$ & $0.02^{* *}$ & $0.05^{* *}$ & 0.23 & 11.76 \\
\hline Italy & 0.35 & 0.11 & 0.56 & 0.42 & 13.75 \\
\hline
\end{tabular}

${ }^{*},{ }^{* *}$ denote significant influence at the $10 \%$ and $5 \%$ level of significance respectively. The Ljung-Box Q* test for autocorrelation follows a $\chi^{2}(12)$ distribution under the null hypothesis with $5 \%$ critical value of 21.03 . 
The first feature to note of Table 3 is that own past effects on real estate returns are only registered for the Netherlands and France. In the other three countries, past values of real estate returns do not significantly influence contemporaneous returns. Setting aside own lags, for the UK, only the term spread variable, for Belgium only the GEYR and dividend yield, for the Netherlands only the GEYR, and only the term spread and the GEYR for France, have any significant explanatory power. In the case of Italy, none of the lagged series, including the real estate returns themselves, have any in-sample predictive ability. Such a result would suggest that the VAR model would be expected to perform relatively poorly for Italy and relatively well for France in the out of sample forecasting exercise. These results, however, highlight the importance of the GEYR as this variable appears significant in three out of the five countries. The last column of Table 3 provides Ljung-Box $Q^{*}$ tests statistics for autocorrelation in the residuals of the real estate equations of the estimated VAR models. As can be seen, none of the statistics are significant (even at the 10\% level) and therefore the models can be assumed to be capturing all of the linear temporal dependencies in the returns ${ }^{1}$.

Further information about the relationships between the pre-specified variables and property returns is generated by variance decompositions and impulse responses. Variance decompositions seek to determine the proportion of the changes in the real estate return series can be attributed to changes in each of the lagged explanatory variables. Utilising one-month ahead forecasts of returns that are produced by the VAR, this technique estimates the proportion of the forecast error attributed to innovations in returns and the proportion attributed to other variables. Table 4 presents the forecast error decompositions for the real estate equations in the VARs tracked up to 24 periods (months) ahead. Since the ordering of the variables can have an impact upon the estimated variance decompositions, we employ 2 orderings that are the exact opposite of one another - these are Order I: real estate returns, GEYR, term structure, dividend yield and Order II: dividend yield, term structure, GEYR, real estate returns.

\footnotetext{
${ }^{1}$ The Ljung-Box test was also applied to the residuals of the other equations in the VARs and it was similarly
} 
Table 4: Decomposition of real estate return forecast variances

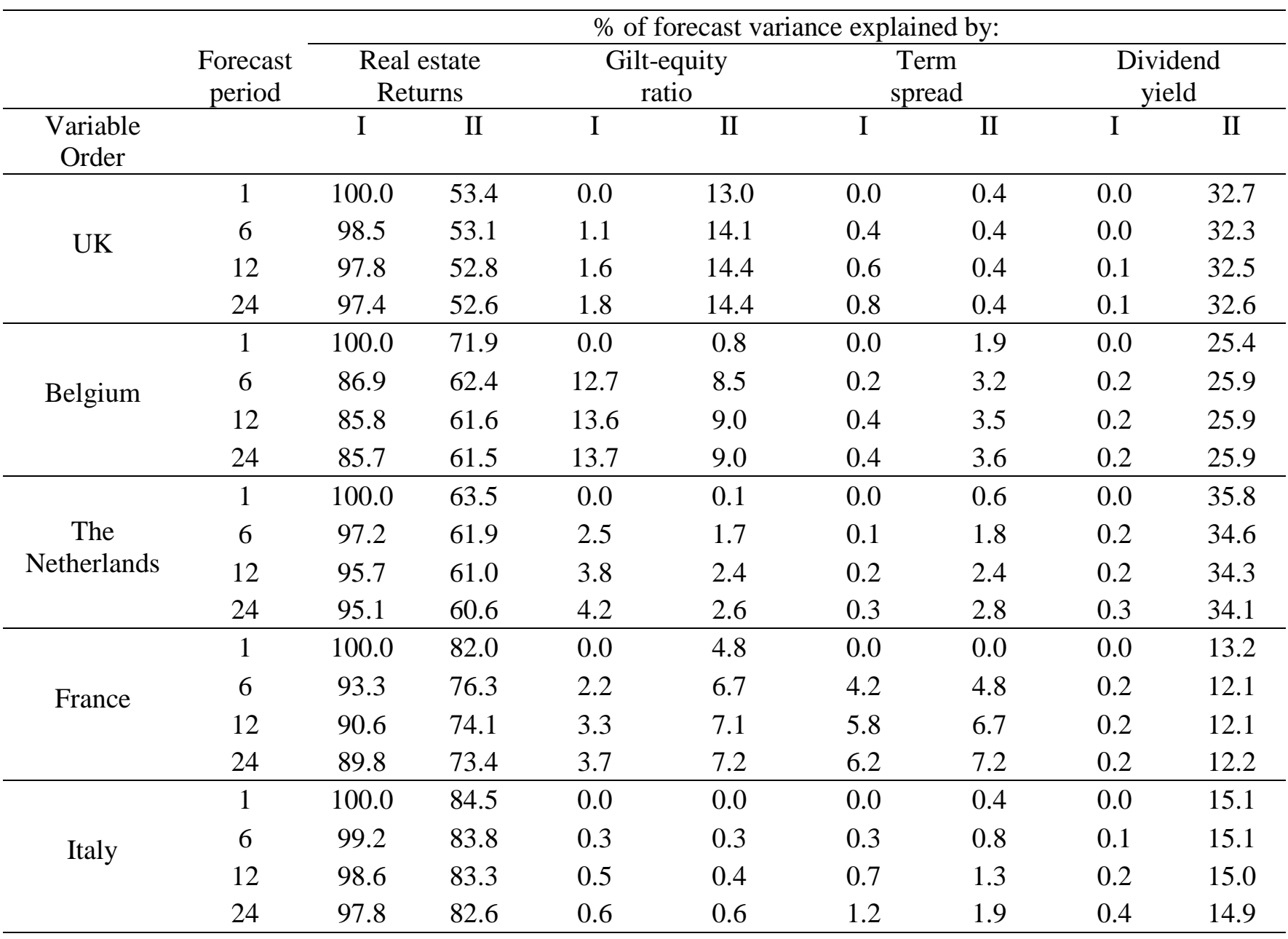

The results of the variance decompositions are seen to broadly follow those of the $F$-tests for all countries but the UK. From the results presented in Table 4, a number of observations are made:

(i) Own lags of real estate returns explain a significant proportion of the forecast error variance of the return forecasts produced by the VAR across all countries. Order I demonstrates the immediate and large explanatory power of lags of real estate returns. Order II confirms that this is not an artefact of the ordering since again own lags of returns account for a significant amount of the forecast variation. For instance in the case of the UK, even after 24 months, own lags of real estate returns explain over $97 \%$ of the forecast error variance when Order I is used and about 53\% when estimates are obtained from Order II.

(ii) The term structure that was picked by the $F$-tests did not have any explanatory power under variance decomposition for either variable ordering. A rather small contribution is observed for France.

(iii) The dividend yields appear to have no explanatory power for any of the real estate series according to the variance decompositions if it is placed last in the variable ordering (Order 
I), while it can explain as much as a third of the forecast error variance if it is placed first (a sign of inconclusive influence on returns).

(iv) The GEYR explains the largest proportion of the real estate forecast error variance considering both variable orderings together (aside for the own lags) in Belgium and France although in the latter the term spread is a slightly better predictor. The GEYR has also a marginal explanatory power for Dutch returns.

To summarise, corroborating the results of the $F$-tests, none of the financial indicators examined are able to consistently explain the variation in indirect real estate returns.

\section{Figure 2: Impulse-Response Functions}

Response of UK returns to own shocks
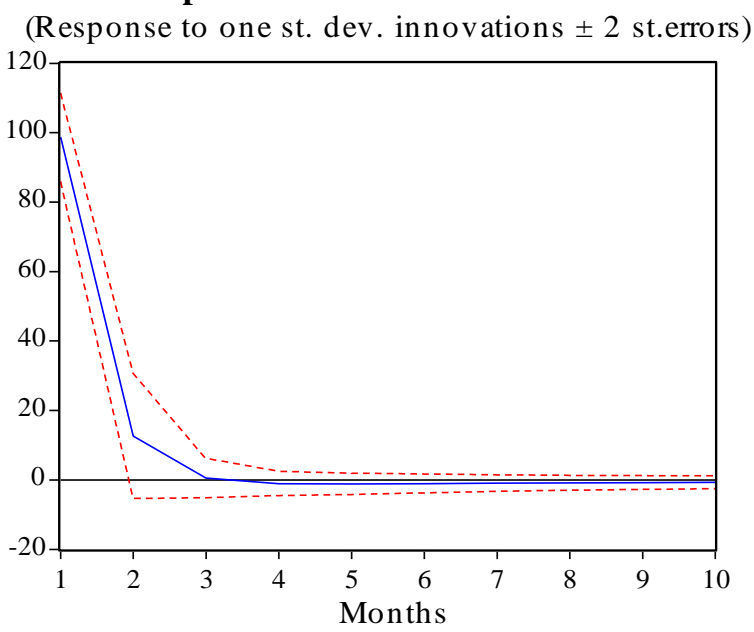

Response of Dutch returns to dividend yield (Response to one st.dev. innovations \pm 2 st.errors)

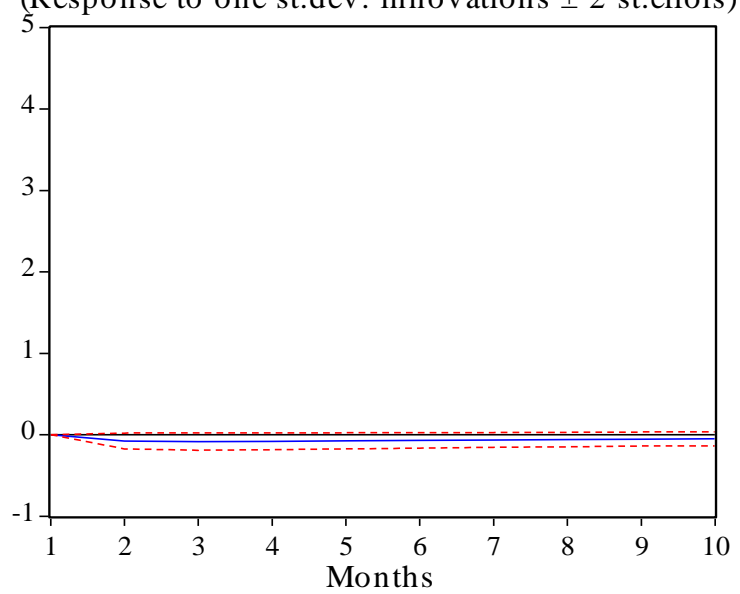

Response of French returns to term structure (Response to one st.dev. innovations \pm 2 st.errors)

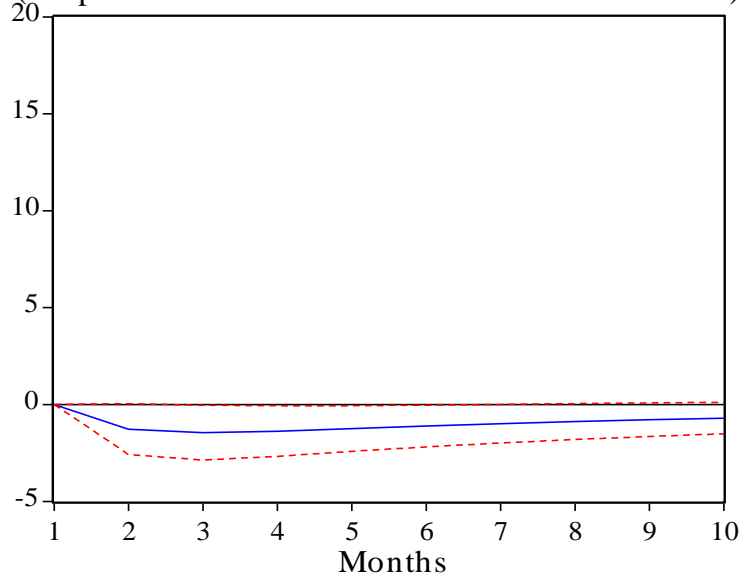

Response of Belgian returns to gilt-equity ratio (Response to one st.dev. innovations \pm 2 st.errors)

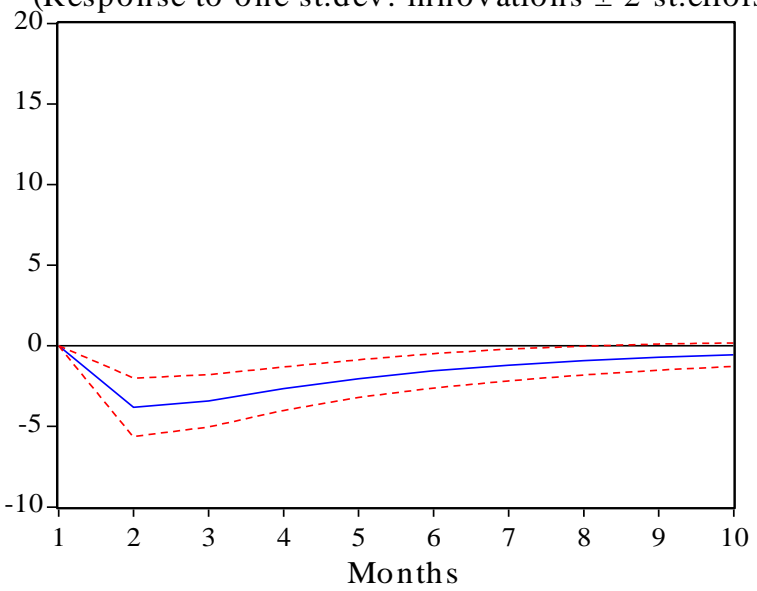

The reaction of returns to innovations is studied further through the computation of impulse responses, which seek to determine the effect that a one-unit shock of each explanatory variable will have upon the 
real estate return series over time. A shock in the error term (by one standard deviation) of the return equation will affect returns both in the current as well as future periods. Similarly a shock in the error terms of the equations for each of the financial variables in the VAR will affect returns since all variables (their lags) are present in the return equations. Selected impulse-response functions for the real estate returns following separate unit shocks to each variable in the VAR are presented in Figure 2 using ordering I, together with \pm 2 standard error confidence bands for up to 10 steps ahead ${ }^{2}$. It is possible to say that the real estate series appear to be positively related to their previous values for at least two months since the response to a unit real estate innovation is positive and significant as it is illustrated for UK returns in Figure 2 (the top left panel). A similar observation is made for the return series in the other European markets. Hence in all cases, the results are in line with the variance decomposition analysis.

By contrast, the three financial ratios appear to have a negative impact on real estate returns for most countries (however a negligible positive impact is recorded for the term structure on UK returns). The impact is not, however, significant in most cases as computation of the $F$-tests for exclusion of variables (or zero coefficients) and variance decompositions showed. In all instances but the UK, an increase in the term spread (i.e. an increase in long rates relative to short rates) causes a fall in the real estate index, and significantly so for France (top right panel of Figure 2). Variance decompositions had established a small effect for France only. An increase in the general market dividend yield has a negative but statistically insignificant impact on future values of the real estate returns for all countries. This insignificant impact is illustrated in the case of Dutch returns in Figure 2. Variance decompositions also produced inconclusive results for the impact of the dividend yield. A rising GEYR appears to lead to falling property prices for all countries, and significantly so for Belgium (up to 7 months ahead), France (for up to 3 months) and the Netherlands (up to 8 months). In the case of the UK, the impulse responses show that the GEYR has the largest impact of the three financial indicators on UK returns.

The negative sign of the dividend yield is as expected. A falling overall market dividend yield signifies improved expectations that have a positive effect on stocks. The negative impact of the gilt-equity yield ratio is also in accordance with expectations. If this ratio rises significantly, stocks are considered expensive and investors switch to bonds. The negative sign that the impulse response analysis established for the term structure in all instances but the UK was not expected. The analysis of Estrella and Hardouvelis (1991) implies a positive relationship between stock prices and the magnitude of the term structure (a flattening yield curve associated with lower share prices and vice versa). A positive relationship was established by the study of Brooks, Tsolacos and Lee (2000) who followed a different methodology to examine cyclical co-movements between property stock assets and financial variables

\footnotetext{
${ }^{2}$ Similar impulse response functions were generated for shocks to all equations in the VAR for each country, but
} 
in the UK. However, since the term structure is only significant in France, there may be specific circumstances in the French environment that relate real estate stock returns inversely to the spread of French interest rates.

\subsection{Forecast performance}

Following the examination of the influence of predetermined variables within a VAR framework, the assessment of the out of sample forecast performance of the competing methodologies was conducted.

Table 5 presents the mean errors, the root mean squared errors and the mean absolute errors for 1,3 , and 6-step ahead forecasts respectively. Numbers in bold indicate the method that performs best for the given forecast horizon and forecast accuracy measure.

all showed the same broad patterns and thus only a selection is shown in the interests of brevity. 
Table 5: Forecast Accuracies

Panel A: One-step Ahead Forecast Error Measures

\begin{tabular}{|c|c|c|c|c|c|c|}
\hline & & UK & Belgium & Netherlands & France & Italy \\
\hline & VAR & 1.05 & 0.73 & 1.07 & 0.73 & 0.39 \\
\hline & Neural Net & 1.16 & 0.81 & 0.74 & 0.95 & 2.49 \\
\hline Mean & $\mathrm{AR}(\mathrm{SIC})$ & 0.69 & 1.22 & 1.56 & 0.54 & 4.29 \\
\hline \multirow[t]{2}{*}{ Errors } & AR(AIC) & 1.87 & 0.43 & 2.31 & 0.96 & 3.94 \\
\hline & RWD & 0.26 & 0.38 & 0.67 & 0.26 & 2.23 \\
\hline Root & VAR & 4.67 & 3.44 & 4.00 & 4.68 & 10.03 \\
\hline Mean & Neural Net & 4.32 & 3.49 & 3.39 & 3.28 & 9.48 \\
\hline Squared & $\mathrm{AR}(\mathrm{SIC})$ & 6.57 & 6.18 & 5.38 & 6.16 & 14.31 \\
\hline \multirow[t]{3}{*}{ Errors } & AR(AIC) & 10.28 & 8.26 & 7.53 & 9.54 & 19.18 \\
\hline & RWD & 4.40 & 3.60 & 3.67 & 4.40 & 9.87 \\
\hline & VAR & 3.61 & 2.84 & 3.08 & 3.67 & 7.31 \\
\hline Mean & Neural Net & 3.32 & 2.63 & 2.47 & 2.21 & 6.29 \\
\hline Absolute & $\mathrm{AR}(\mathrm{SIC})$ & 7.30 & 7.09 & 5.86 & 7.02 & 14.22 \\
\hline \multirow[t]{2}{*}{ Errors } & AR(AIC) & 13.63 & 11.57 & 10.03 & 12.80 & 23.95 \\
\hline & RWD & 3.56 & 2.73 & 2.83 & 3.56 & 6.92 \\
\hline \multicolumn{7}{|c|}{ Panel B: Three-step Ahead Forecast Error Measures } \\
\hline & VAR & 0.94 & 0.57 & 1.08 & 0.77 & 0.49 \\
\hline & Neural Net & 1.75 & 1.23 & 1.24 & 1.21 & 2.37 \\
\hline Mean & $\mathrm{AR}(\mathrm{SIC})$ & -0.18 & 1.17 & 1.44 & 0.60 & 4.43 \\
\hline \multirow[t]{2}{*}{ Errors } & $\mathrm{AR}(\mathrm{AIC})$ & -1.93 & 0.78 & 2.57 & 0.52 & 6.39 \\
\hline & RWD & 0.28 & 0.23 & 0.42 & 0.28 & 2.28 \\
\hline Root & VAR & 4.77 & 3.78 & 4.00 & 4.93 & 10.01 \\
\hline Mean & Neural Net & 4.32 & 3.59 & 3.66 & 3.50 & 9.63 \\
\hline Squared & $\mathrm{AR}(\mathrm{SIC})$ & 6.72 & 5.94 & 5.47 & 6.28 & 14.15 \\
\hline \multirow[t]{3}{*}{ Errors } & $\mathrm{AR}(\mathrm{AIC})$ & 9.49 & 8.07 & 7.78 & 10.11 & 19.93 \\
\hline & RWD & 4.65 & 3.49 & 3.65 & 4.44 & 9.95 \\
\hline & VAR & 3.91 & 3.01 & 3.02 & 4.02 & 7.17 \\
\hline Mean & Neural Net & 3.69 & 2.70 & 2.77 & 2.40 & 6.53 \\
\hline Absolute & AR(SIC) & 7.55 & 6.85 & 5.91 & 7.16 & 14.36 \\
\hline \multirow[t]{2}{*}{ Errors } & $\mathrm{AR}(\mathrm{AIC})$ & 12.98 & 11.27 & 10.03 & 13.72 & 25.63 \\
\hline & RWD & 3.59 & 2.58 & 2.83 & 3.59 & 7.06 \\
\hline \multicolumn{7}{|c|}{ Panel C: Six-step Ahead Forecast Error Measures } \\
\hline & VAR & 0.52 & 0.50 & 1.27 & 0.52 & -0.14 \\
\hline & Neural Net & 1.70 & 1.31 & 1.29 & 1.18 & 2.23 \\
\hline Mean & $\mathrm{AR}(\mathrm{SIC})$ & 0.14 & 0.91 & 1.71 & 0.23 & 3.20 \\
\hline \multirow[t]{2}{*}{ Errors } & $\mathrm{AR}(\mathrm{AIC})$ & 0.23 & 1.68 & 1.48 & 0.25 & 5.24 \\
\hline & RWD & 0.09 & 0.24 & $\mathbf{0 . 4 3}$ & 0.09 & 1.60 \\
\hline Root & VAR & 4.57 & 4.02 & 4.45 & 4.81 & 9.92 \\
\hline Mean & Neural Net & 4.67 & 3.74 & 3.89 & 3.60 & 9.69 \\
\hline Squared & $\mathrm{AR}(\mathrm{SIC})$ & 6.61 & 6.14 & 5.79 & 6.34 & 14.03 \\
\hline \multirow[t]{3}{*}{ Errors } & AR(AIC) & 9.98 & 7.70 & 8.35 & 8.94 & 19.19 \\
\hline & RWD & 4.44 & 3.54 & 3.67 & 4.44 & 9.90 \\
\hline & VAR & 3.72 & 3.07 & 3.64 & 3.93 & 6.93 \\
\hline Mean & Neural Net & 3.83 & 2.86 & 3.07 & 2.53 & 6.66 \\
\hline Absolute & $\mathrm{AR}(\mathrm{SIC})$ & 7.66 & 6.73 & 6.51 & 7.44 & 6.83 \\
\hline \multirow[t]{2}{*}{ Errors } & AR(AIC) & 13.72 & 10.63 & 11.34 & 12.31 & 23.18 \\
\hline & RWD & 3.68 & 2.63 & 2.88 & 3.67 & 6.83 \\
\hline
\end{tabular}


Overall, the most important features of the results appear to be the supremacy of the simple random walk with drift and neural network models, and the relatively poor performance of the profligate univariate ARMA models under all error measures. In all cases, the mean errors are positive (except for the 3-month prediction in the case of the UK), indicating that on average the forecasts were always above the actual out-turns, so that the forecasts were underestimates. This seems intuitive given that the European property market returns were considerably lower towards the end of our sample compared with earlier periods. The performance of the VAR model across the board is relatively poor and in all cases is outperformed by the other methodologies. To a degree, this is not surprising since the variance decomposition and impulse responses did not establish strong linear links between the financial indicators and real estate returns.

For one-step ahead forecasts, two of the forecast assessment criteria - the mean absolute error (MAE) and the root mean squared error (RMSE) - select the neural network for all countries. The mean error selected the random walk model for all countries except Italy where the VAR model is the best performing. Overall therefore, the neural network is the best model for one step ahead forecasts of real estate returns.

For three-step ahead forecasts, the pattern of the results is not as clear as in the previous case. The neural network is still the most successful forecasting methodology in France and Italy (selected by two of the three forecast assessment metrics), whereas the random walk model is chosen for the remaining three countries. Again, the univariate ARMA models and the VAR do not provide better forecasts than the other two approaches.

Finally, an evaluation of the six-month forecasts reveals that all three criteria choose the random walk model for the UK, Belgium and the Netherlands. For the other two countries, the neural network is selected on the basis of two of the three criteria.

The out of sample forecast evaluation exercise clearly indicates that the neural network and the random walk model are the most successful forecasting frameworks. Across all forecast horizons, the neural network model incorporating the additional financial market information embodied in the GEYR, term structure and dividend yield is the single best performing methodology in France and Italy. It is interesting to observe, however, that in Italy, the VAR incorporating all these variables produces the lowest mean errors. This implies that the forecast errors of the VAR cancel each other out but large errors in particular months over the forecast period inflate the values of the RMSE and the MAE. The neural network is also chosen for the other countries - the UK, Belgium and the Netherlands when one- 
step ahead forecasts are considered. For the two longer horizons, the random walk model forecasts most accurately.

As one would expect, the forecast errors in general increase progressively as the prediction horizon is lengthened. For example, the RMSEs for the neural network for France for the one-, three-, and six-step ahead forecasts are $3.28,3.50$ and 3.60 respectively.

\section{Conclusions}

The main emphasis in the present study is on assessing the forecasting performance of models of real estate stock returns. The motivations for this line of enquiry are twofold. First, evidence in the existing literature suggests that the significance of predetermined variables that are related to stock price and return variation appears to be disposed to the methodology, sample period and type of return or excess return series used. It is unclear how successful such models would be when used for out of sample forecasting. Second, very few studies have employed neural networks to forecast time-series of real estate asset returns. The potential of these models to represent an additional useful tool for fund managers has not been explored.

This study assesses the relative performance of four models employed to forecast real estate stock returns in the UK, Belgium, the Netherlands, France and Italy. In the first stage of the empirical investigation, the significances and the signs of the influence of the gilt-equity yield ratio, the term structure of interest rates and the overall stock market dividend yield on real estate returns in each market are examined. This is accomplished by deploying a VAR methodology and through the computation of $F$-statistics for variable significance, variance decompositions and impulse responses. Consistent with the results of existing empirical work, we find that none of the indicators receives overwhelming support. Moreover, the significance of the indicators differs across countries implying that returns in European markets are not driven by harmonised responses to indicator signals.

The gilt-equity ratio (GEYR), which is the variable least commonly incorporated in models of real estate return predictability, is overall found to be the most successful (apart from the lagged real estate returns themselves) in explaining returns in each of the markets except for Italy and the UK. A recent study on UK indirect real estate returns (Brooks and Tsolacos, 2001b), provided supporting evidence for the role of GEYR real estate return movements although some instability was evident in terms of positive and negative effects. In this study, it is only a specific ordering in variance decompositions that supports the GEYR. A possible explanation for this discrepancy is the different sample period in the two studies. The data sample in the present study is 1991 to beginning of 2001 whereas in that of Brooks and Tsolacos (2001b), it was 1968 to the beginning of 1998. On this evidence it can be argued that the effect of GEYR on securitised real estate in the UK has been stronger before the 1990s. The 
term structure seems to have an influence on returns in France and less so in the UK. This is broadly a similar result to that reached by Brooks and Tsolacos (2001a) in that the interest rate spread does not explain more than $10 \%$ of the forecast error variance of indirect real estate returns in the UK. The dividend yield is only significant in Belgium although this effect is not supported by all tests. Again, this is in line with the findings of the existing statistical literature on real estate returns. Perhaps the relationship between real estate returns and the dividend yield is contemporaneous as established in the study of Brooks, Tsolacos and Lee (2000). An implication of these findings is that analysts will have to place different weights to alternative indicators for modelling and predicting indirect real estate returns. However, the GEYR series should receive particular attention.

The results of the forecast exercise reveal that a random walk model with a drift is generally a better predictor of real estate returns in all market environments when a forecast horizon of six months is considered. For one-month ahead forecast horizons, the analysis shows that the neural network model is clearly the most successful. Nonetheless, the random walk model over this time horizon is still the second most successful approach. As the forecast horizon lengthens, the random walk model becomes stronger. For three-months ahead, the random walk model is the strongest in Belgium and the strongest in the Netherlands and the UK on the basis of two out of three criteria. For six-months ahead, the random walk model is the best forecast methodology in the UK, Belgium and the Netherlands but for France and Italy the neural network remains the most successful. If the success of a more general forecasting model that incorporates publicly available information is considered as a sign of market inefficiency, then it can be argued that the French and Italian markets are more inefficient compared to the other three and they potentially offer more profitable trading opportunities. This is useful information for European funds with a greater interest in indirect real estate securities such as those in the Netherlands.

There are important implications emanating from this investigation for fund managers with interests in real estate stocks and in particular for those who incorporate quantitative forecasts into their decision making process. Given the wealth of modelling procedures and indicators that are available, a formal evaluation of the forecast performance of real estate return models should always be pursued to achieve greater confidence in the methodologies finally adopted. This evaluation should also be undertaken over different forecast horizons. The comparative forecast study of Brooks and Tsolacos (2001b) in the UK showed that a VAR containing the term structure of interest rates and the GEYR outperformed ARMA models for one month forecasts but not over six month horizons (although the VAR was still the most successful in predicting the correct signs). In this study, the VAR was also more successful than the ARMA specifications in the UK. However, the poor performance of the ARMA and VAR models when compared with the neural network and random walk model under all forecast error criteria and forecast time horizons raises the research issue of how satisfactory is the relative forecast 
performance of regression models, systems of equations and other testable specifications when comparative forecast analysis is not carried out. An obvious improvement to underperforming linear models of real estate stock returns is to seek indicators that are most suitable in individual international markets. Another route is to explore whether more complex relationships underpin the relationship between real estate returns and these financial indicators.

The present study has shown the potential usefulness of neural networks as a forecasting tool in real estate markets (a finding that conforms with the results of Connellan and James (1998) and Evans, James and Collins (1992)). Their accuracy is suggestive of interactions between real estate returns and financial variables that are of a non-linear nature. Such interactions apparently cannot be captured satisfactorily by a linear VAR model or probably by other linear methodologies. However, this improved accuracy does not come costlessly to the forecaster. Neural networks are not amenable to policy analysis or to exploration, as are VARs and other restrictive models. Indeed, the parameter estimates (the synaptic weights or connections) of a neural network models have no theoretical interpretations and hence problem detection in such models is extremely difficult. Moreover, no asymptotic theory currently exists for the testing of hypotheses concerning the neural network weights. Thus, whilst neural nets seem to work well, their "black box" nature will limit analysts' willingness to use them in practice. Nevertheless, the successful forecast performance of the neural network and random walk methodologies suggests that these approaches can be used as the benchmark forecasting methodologies that alternative specifications of real estate returns should improve upon.

\section{References}

Allen, M.T., Madura, J. and Springer, T.M. (2000) "REIT Characteristics and the Sensitivity of REIT Returns", Journal of Real Estate Finance and Economics 21(2), 141-152.

Barkham, R. and D. Geltner. (1995) "Price Discovery in American and British Property Markets", Real Estate Economics, 23, 21-44.

Berk, J.M. (1998) "The Information Content of the Yield Curve for Monetary Policy: A Survey", The Economist, 146, 303-320.

Bernanke, B.S. (1990) "On the Predictive Power of Interest Rates and Interest Rates Spreads", New England Economic Review November/December, 51-68.

Brooks, C. and Persand, G. (2001) "The Trading Profitability of Forecasts of the Gilt-Equity Ratio", International Journal of Forecasting, 17, 11-29.

Brooks, C. and Tsolacos, S. (2001a) "Linkages between property asset returns and interest rates: evidence for the UK", Applied Economics, 33, 711-719.

Brooks, C. and Tsolacos, S. (2001b) "Forecasting Real Estate Returns Using Financial Spreads", Journal of Property Research, 18, 235-248. 
Brooks, C. and Tsolacos, S. (2000) "Forecasting models of retail rents", Environment and Planning A, $32,1825-1839$.

Brooks, C. and Tsolacos, S. (1999) "The Impact of Economic and Financial Factors on UK Property Performance” Journal of Property Research 16(2), 139-152.

Brooks, S., Tsolacos, S. and Lee, S. (2000) "The Cyclical Relations Between Traded Property Stock Prices and Aggregate Time-Series”, Journal of Property Investment and Finance 18(6), 540-564.

Campbell, J. and Shiller, R. (1988) "The Dividend Price Ratio and Expectations of Future Dividends and Discount Factors," Review of Financial Studies 1, 195-228.

Chan, K.C., Hendershott, P.H. and Sanders, A.B. (1990) "Risk and Return on Real Estate: Evidence from Equity REITs", AREUEA Journal, 18, 431-452.

Chaplin, R. (2000) "Predicting real estate returns: walking backwards into the future", Journal of Property Investment and Finance 18(3), 352-370.

Chaplin, R. (1998) "An ex-post comparative evaluation of office rent prediction models", Journal of Property Valuation and Investment 16(1), 21-37.

Chen, N-F. (1991) "Financial Investment Opportunities and the Macroeconomy", Journal of Finance 46(2), 529-554.

Chen, S., Hsieh, C.H. and Jordan, B.D. (1997) "Real Estate and Arbitrage Pricing Theory: Microvariables vs Derived Factors", Real Estate Economics 25(3), 505-523.

Clare, A.D., Thomas, S.H. and Wickens, M.R. (1994) "Is the Gilt-Equity Yield Ratio Useful for Predicting UK Stock Returns?,” Economic Journal 104, 303-315.

Connellan, O. and James, H. (1998) "Estimated Realisation Price (ERP) by Neural Networks: Forecasting Commercial Property Values" 16, 71-86.

Davis, E.P. and Fagan, G. (1997) "Are financial spreads useful indicators of future inflation and output growth in EU countries?”, Journal of Applied Econometrics 12, 701-714.

Donaldson, G. and Kamstra, M. (1996) "Forecast combining with neural networks", Journal of Forecasting 15, 49-61.

Estrella, A. and Hardouvelis, G.A. (1991) "The term structure as a predictor of real economic activity", Journal of Finance 46, 555-576

Estrella, A. and Mishkin, F.S. (1997) "The predictive power of the term structure of interest rates in europe and the United States: implications for the European Central Bank", European Economic Review 41, 1375-1401.

Evans, A., James, H. and Collins, A. (1992) "Artificial neural networks: an application to residential valuation in the UK", Journal of Property Valuation and Investment, 11, 195-204.

Fama, E.F and French, K.R. (1988) "Dividend Yields and Expected Stock Returns", Journal of Financial Economics 22, 3-25.

Ferson, W. and Harvey, C. (1991) "The Variation of Economic Risk Premiums", Journal of Political Economy 99, 385-415. 
Gerlach, S. and Smets, F. (1997) "The Term Structure of Euro-rates: Some Evidence in Support of the Expectations Hypothesis”, Journal of International Money and Finance, 16, 305-321.

Hardouvelis, G. (1994) "The term structure spread and future changes in long and short rates in the G7 countries”, Journal of Monetary Economics 33, 255-83.

Harvey, C.R. (1988) "The Real Term Structure and Consumption Growth," Journal of Financial Economics 22, 305-333.

Kothari, S.P. and Shanken, J. (1997) "Book-to-Market, Dividend Yield, and Expected Market Returns: A Time-Series Analysis," Journal of Financial Economics 44, 169-203.

Marquardt, D.W. (1963) "An Algorithm for the Least Squares Estimation of Non-linear Parameters" Journal of the Society for Industrial and Applied Mathematics 11, 431-441

McCue, T.E. and Kling, J.L. (1994) "Real estate returns and the macroeconomy: some empirical evidence from real estate investment trust data, 1972-1991”, Journal of Real Estate Research $9(3), 5-32$.

McGough, T., Olkkonen, O. and Tsolacos, S. (2000) "The predictability of office returns in Helsinki", Journal of Property Investment and Finance 18(6), 565-585.

Mei, J. and Liu, C.H. (1994) "The Predictability of Real Estate Returns and Market Timing”, Journal of Real Estate Finance and Economics, 8, 115-135.

Meyer, F.C.N. and Webb, J.R. (1994) "Statistical Properties of Returns: Financial Assets versus Commercial Real Estate", Journal of Real Estate Finance and Economics 8, 267-82.

Mueller, G.R. and Pauley, K.R. (1995) "The Effect of Interest-Rate Movements on Real Estate Investment Trusts", Journal of Real Estate Research 10(3), 319-325.

Levin, E.J. and Wright, R.E. (1998) "The Information Content of the Gilt-Equity Yield Ratio", Manchester School Supplement, 89-101.

Ling, D. and Naranjo, A. (1997) "Economic risk factors and commercial real estate returns", Journal of Real Estate Finance and Economics, 14, 283-307.

Liu, C.H. and Mei, J. (1992) "The predictability of returns on equity REITs and their co-movement with other assets", Journal of Real Estate Finance and Economics 5, 401-18.

Lizieri, C. and Satchell, S. (1997) "Property Company Performance and Real Interest Rates: A RegimeSwitching Approach" Journal of Property Research 14, 85-97.

Myer, F.C.N. and Webb, J.R. (1994) "Retail Stocks, Retail REITs and Retail Real Estate" Journal of Real Estate Research 9, 65-84.

Pesaran, H. and Timmerman, A. (1995) "Predictability of stock returns: robustness and economic significance", The Journal of Finance 50(4), 1201-1228.

Peterson, J.D. and Hsieh, C.H. (1997) "Do common factors in returns on stocks and bonds explain returns on REITs?”, Real Estate Economics 25(2), 321-345.

Qi, M., and Maddala, G.S. (1999) "Economic factors and the stock market: a new perspective", Journal of Forecasting 18, 151-166. 
Seiler, M.J., Webb, J.R. and Myer, F.C.N. (1999a) “Are EREITs real estate?”, Journal of Real Estate Portfolio Management 5, 171-82.

Seiler, M.J., Webb, J. R. and Myer, F.C.N. (1999b) "Diversification Issues in Real Estate Investment", Journal of Real Estate Literature 5, 171-82.

Stevenson, S. (2001) "The Long-Term Advantages to Incorporating Indirect Securities in Direct Real Estate Portfolios", Journal of Real Estate Portfolio Management 7(1), 5-16.

Tay, D.P.H. and Ho, K.H.H. (1991) "Artificial intelligence and the mass appraisal of residential apartments", Journal of Property Valuation and Investment 10, 525-540.

Wilson, P., Okunev, J. Ellis, G. and Higgins, D. (2000) "Comparing univariate forecasting techniques in property markets", Journal of Real Estate Portfolio Management 6(3), 283-306.

Wong, K.C., So, Albert T.P. and Hung, Y.C. (2002) "Neural network vs. hedonic price model: appraisal of high-density condominiums", in Real Estate Valuation Theory by Wang, K. and Wolverton M.L. (eds), pp.181-198, KAP, Boston.

Worzala, E., Lenk, M. and Silva, A. (1995) "An exploration of neural networks and its application to real estate valuation”, Journal of Real Estate Research 10(2), 185-201. 